\title{
A COMPARISON OF CEILING JET TEMPERATURES MEASURED IN AN AIRCRAFT HANGER TEST FIRE WITH TEMPERATURES PREDICTED BY THE DETACT-QS AND LAVENT COMPUTER MODELS
}

William D. Walton

Kathy A. Notarianni

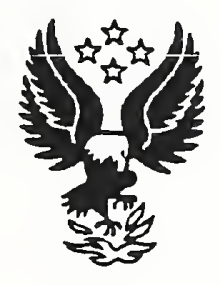

Prepared for:

U.S. Fire Administration

Emmitsburg, MD 21727

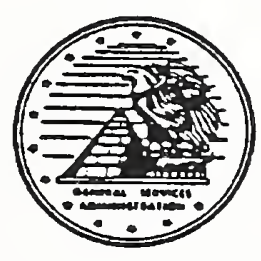

General Services Administration

Public Building Service

Office of Real Property Management and Safety Washington, DC 20405 

A COMPARISON OF CEILING JET

TEMPERATURES MEASURED IN AN

AIRCRAFT HANGER TEST FIRE WITH

TEMPERATURES PREDICTED BY THE

DETACT-QS AND LAVENT COMPUTER

MODELS

William D. Walton

Kathy A. Notarianni

Building and Fire Research Laboratory

Gaithersburg, MD 20899

January 1993

Prepared for:

U.S. Fire Administration

Emmitsburg, MD 21727

U.S. Department of Commerce

Ronald H. Brown, Secretary

National Institute of Standards and Technology

John W. Lyons, Director
General Services Administration

Robert Lee Jones, Acting Administrator

Public Buildings Service

P. Gerald Thacker, Acting Commissioner

Office of Real Property Management and Safety

Washington, D.C. 20405 

LIST OF TABLES $\ldots \ldots \ldots \ldots \ldots \ldots \ldots \ldots \ldots \ldots \ldots \ldots \ldots \ldots \ldots \ldots$

LIST OF FIGURES $\ldots \ldots \ldots \ldots \ldots \ldots \ldots \ldots \ldots \ldots \ldots \ldots \ldots \ldots \ldots$

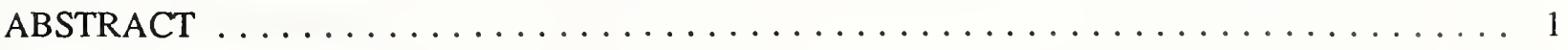

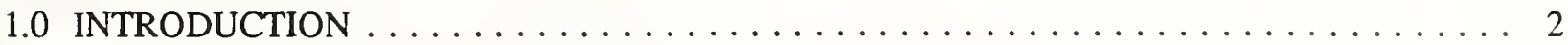

2.0 TEST CONFIGURATION AND INSTRUMENTATION $\ldots \ldots \ldots \ldots \ldots \ldots \ldots$

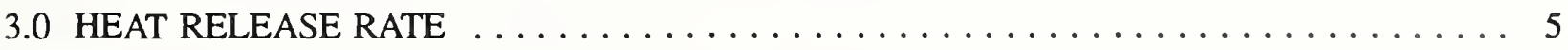

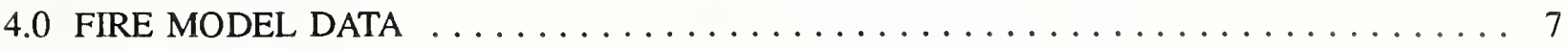

5.0 COMPARISON OF PREDICTED AND MEASURED CEILING JET TEMPERATURES . . . 8

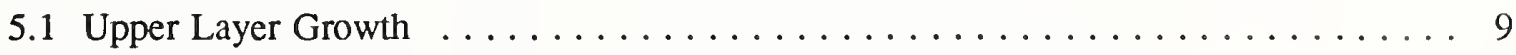

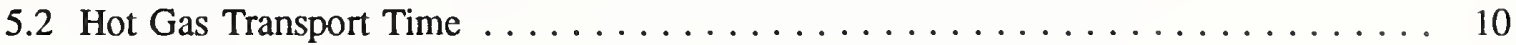

5.3 Distance of Thermal Device Below the Ceiling $\ldots \ldots \ldots \ldots \ldots \ldots$

6.0 SENSITIVITY OF MODEL PREDICTIONS TO HEAT RELEASE AND RTI INPUTS . . . 11

7.0 SUMMARY AND CONCLUSIONS $\ldots \ldots \ldots \ldots \ldots \ldots \ldots \ldots \ldots \ldots$

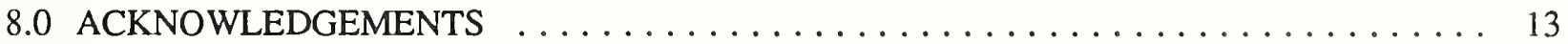

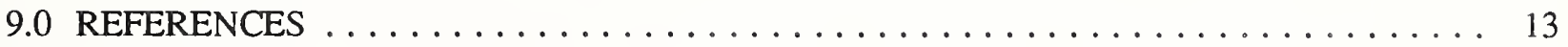




\section{LIST OF TABLES}

Page

Table 1. Predicted plume properties $\ldots \ldots \ldots \ldots \ldots \ldots \ldots \ldots \ldots \ldots \ldots$

Table 2. Maximum measured plume temperatures . . . . . . . . . . . . . . . 14

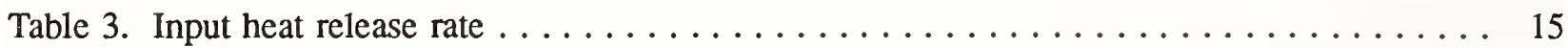

Table 4. DETACT-QS input values . . . . . . . . . . . . . . . . . 15

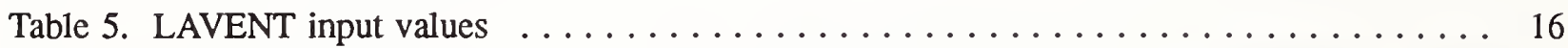

Table 6 . Predicted values at $60 \mathrm{~s} \ldots \ldots \ldots \ldots \ldots \ldots \ldots \ldots \ldots \ldots \ldots \ldots$ 
Figure 1. Plan view of main hanger bay $\ldots \ldots \ldots \ldots \ldots \ldots \ldots \ldots \ldots \ldots$

Figure 2. Temperatures at $0 \mathrm{~m}$ radial distance $\ldots \ldots \ldots \ldots \ldots \ldots$

Figure 3. Temperatures at $2.7 \mathrm{~m}$ radial distance $\ldots \ldots \ldots \ldots \ldots \ldots \ldots$

Figure 4. Temperatures at $5.5 \mathrm{~m}$ radial distance $\ldots \ldots \ldots \ldots \ldots \ldots \ldots \ldots$

Figure 5. Temperatures at $8.2 \mathrm{~m}$ radial distance $\ldots \ldots \ldots \ldots \ldots \ldots \ldots \ldots \ldots \ldots$

Figure 6 . Temperatures at $11.0 \mathrm{~m}$ radial distance $\ldots \ldots \ldots \ldots \ldots \ldots \ldots \ldots$

Figure 7. Predicted upper layer temperature . . . . . . . . . . . . . . . . . . . . 24

Figure 8. Gas temperatures for all radial distances, $380 \mathrm{~mm}$ below ceiling . . . . . . . . . 25

Figure 9. Temperatures at $11.0 \mathrm{~m}$ radial distance with time shift $\ldots \ldots \ldots \ldots$

Figure 10. Temperatures at $5.5 \mathrm{~m}$ radial distance at 3 elevations $\ldots \ldots \ldots \ldots \ldots$

Figure 11. Temperatures at $5.5 \mathrm{~m}$ radial distance with varying heat release rates . . . . . . . 28

Figure 12. Temperatures at $5.5 \mathrm{~m}$ radial distance with varying RTI . . . . . . . . . . . . . . . 29 
A COMPARISON OF CEILING JET TEMPERATURES MEASURED IN AN AIRCRAFT HANGER TEST FIRE WITH TEMPERATURES PREDICTED BY THE DETACT-QS AND LAVENT COMPUTER MODELS

\author{
William D. Walton and Kathy A. Notarianni \\ Building and Fire Research Laboratory, \\ U.S. National Institute of Standards and Technology
}

\begin{abstract}
Predictions of the DETACT-QS and LAVENT computer fire models are compared to temperature measurements made during the calibration of the fire detection system in a military aircraft hanger. Two $3.34 \mathrm{~m}^{2}$ isopropyl alcohol pool fire tests of 60 second duration were conducted in the $37 \mathrm{~m}$ by $40 \mathrm{~m}$ by $14 \mathrm{~m}$ high main hanger bay. Brass disks with a known thermal response time index (RTI) were used to simulate the thermal element in a sprinkler or heat detector. Measurements were made of centerline plume temperatures, and ceiling jet gas and disk temperatures at radial distances of $0,2.7,5.5,8.2$, and $11.0 \mathrm{~m}$ from the centerline of the fire, $380 \mathrm{~mm}$ below the ceiling. At a radial distance of $5.5 \mathrm{~m}$, measurements of ceiling jet gas temperatures were also made 150 and $610 \mathrm{~mm}$ below the ceiling. Comparisons of predictions and measurements demonstrate some of the strengths and weakness of DETACT-QS and LAVENT for this fire scenario.
\end{abstract}

Key words: building technology, detector response; computer models; fire models; fire plumes; fire tests; fire tests; pool fires; response time; sprinkler response 


\subsection{INTRODUCTION}

The prediction of sprinkler and/or thermal detector activation times is an important element of many fire protection analyses. The activation of sprinklers and detectors is used to wam occupants of a potential fire, to initiate suppression, and to summon outside assistance. Although sprinklers, heat detectors and fusible links may appear very different and are used for different purposes, they are all thermal detectors which respond to the heat generated by a fire. By characterizing thermal detectors in a general manner, the same form of analysis can be applied to sprinklers, heat detectors and fusible links.

The method of analysis of the response of thermal devices was developed by Heskestad[1] $]^{1}$ and a simplified summary is provided by Schifiliti[2]. Heat is transferred to a thermal device by conduction, convection and radiation. For the simplest analysis of thermal devices totally submerged in a hot gas flow it is assumed that the contributions from conduction and radiation are small and can be neglected. Convective heat transfer to the thermal detector is a function of the effective area of the heat responsive element, the convective heat transfer coefficient, the velocity of the hot gas passing the element, and the temperature difference between the hot gas and the element. Since the thermal conductivity of the heat responsive element is high and the mass is relatively low, it is assumed that the element can be treated as a lumped mass with uniform temperature throughout whose temperature rise is a function of its mass, specific heat and the heat transfer rate. A time constant, $\tau$, can be assigned to a thermal detector which is a function of the detector mass, area, and specific heat, and the convective heat transfer coefficient. Since the convective heat transfer coefficient is a function of the gas velocity, $\tau$ is not a property of the thermal detector. For common shapes of heat sensitive elements and expected gas velocities the convective heat transfer coefficient is approximately proportional to the square root of the gas velocity. To separate the dependence on velocity from properties of the thermal detector, Heskestad has defined the response time index, RTI, for a thermal detector as the product of the detector time constant, $\tau$, evaluated at a specific velocity, and the square root of that velocity. The RTI of a thermal detector over a broad range of conditions is nearly constant and is dependent only upon the construction of detector itself. Therefore, the temperature rise of a thermal detector becomes a function of the RTI of the detector, the velocity of the hot gas flowing past the detector, and the temperature difference between the hot gas and the detector.

The temperature and velocity of the gas flowing past a detector is obtained from an analysis of the fire. A portion of the heat generated by a fire is transferred back to the fuel, where it contributes to the fuel pyrolysis process. Generally the remainder of the heat leaves the fire area either convected in the rising fire plume or in the form of radiation. At the start of an enclosure fire the majority of the heat reaching ceiling mounted thermal detectors is convected by the fire plume, while only a small fraction comes from radiation. As the plume rises from the fire it grows in cross-sectional area and mass due to the entrainment of surrounding air. At the same time the temperature and velocity of the plume decrease with height. The time averaged temperature and velocity profiles across the plume are approximately Gaussian, with the highest values found at the center. When the plume reaches the ceiling it spreads radially from the centerline of the fire to form a ceiling jet. The ceiling jet continues to cool as it moves away from the centerline of the fire due to both entrainment and heat transfer to the ceiling. The velocity of the ceiling jet also decreases with increasing distance from the fire. The velocity and temperature profiles

\footnotetext{
${ }^{1}$ Numbers in brackets indicate literature references at the end of the paper.
} 
normal to the ceiling in the direction of jet flow are no longer Gaussian, but, moving down from the ceiling, increase rapidly to a peak value, then fall off slowly to the free stream conditions.

It is possible to predict the temperature and velocity of the ceiling jet reaching a thermal detector from fundamental principles using techniques such as field modeling. At the present time these techniques are not practical for general engineering practice. For engineering purposes correlations based on experiments are used to predict the ceiling jet temperature and velocity. The most commonly used correlations were developed by Alpert[3], in which the maximum ceiling jet temperature and velocity are predicted for smooth unconfined ceilings as a function of steady state heat release rate of the fire, height of the ceiling above the fuel, and radial distance from the centerline of the fire.

The prediction of thermal detector activation times is normally accomplished through the use of either specialized computer fire models or activation routines included as part of a generalized fire model. The correlations of Alpert were used by Evans in the computer model DETACT-QS[4] (DETector ACTuation Quasi-Steady) to predict the operation of thermal detectors on smooth unconfined ceilings with fires of arbitrary heat release rates. DETACT-QS assumes that the steady-state correlations can be applied to a growing fire over small time intervals, the transport time of heat from the fire to the thermal detector can be neglected, the thermal detector is subject to the maximum temperature and velocity of the ceiling jet, and there is no heat contribution from a hot upper layer. DETACT-QS is probably the most widely used method for predicting the response of thermal detectors with fires of arbitrary heat release rate. Although the correlations of Alpert were based on ceilings up to $16 \mathrm{~m}(51 \mathrm{ft})$ above the base of the fire, the predictions of DETACT-QS have not been compared with experimental measurements for ceiling heights approaching that height.

A second computer model for predicting the activation of thermal devices is LAVENT (Link-Activated VENT) developed by Cooper and Davis[5,6]. LAVENT is a two-zone fire model with a routine to calculate the activation time of thermal devices based on expressions developed by Cooper. Like DETACT-QS, LAVENT assumes the steady-state correlations can be applied to a growing fire over small time intervals, and that the transport time from the fire to the thermal detector can be neglected. Unlike DETACT-QS, LAVENT accounts for the position of the thermal detector in the ceiling jet and accounts for the contribution of heat from the hot upper layer to the fire plume. Like DETACT-QS the predictions of LAVENT have not been compared with experimental measurements for ceiling heights on the order of $15 \mathrm{~m}(50 \mathrm{ft})$.

The responsibility for determining the suitability of using a particular computer fire model in a given situation falls on the user of the model. The comparison of model predictions with a wide range of experimental data is critical to the user in making a determination of model suitability. Further it allows model developers to examine the accuracy of the models and identify the need for future model development. Fire experiments are expensive to conduct, and it is difficult to locate buildings other than specialized fire test facilities in which fire tests can be conducted. The Building and Fire Research Laboratory at the National Institute of Standards and Technology was given the opportunity to make measurements during fire calibration tests of the heat detection system in an aircraft hanger. Although the tests were of relatively short, 60 second, duration and the quantity and type of instrumentation was limited by the installation time available, a useful set of data was obtained. The data from the fire tests were then compared to the predictions of the DETACT-QS and LAVENT models. The results of the heat detector calibrations were not made available to the authors. 


\subsection{TEST CONFIGURATION AND INSTRUMENTATION}

The fire tests were conducted in the main hanger bay of an military aircraft maintenance facility. A plan view of the main hanger bay is shown in figure 1. The interior dimensions of the bay were 37.2 by $40.2 \mathrm{~m}$ (122 by $132 \mathrm{ft})$, with a ceiling height of $14 \mathrm{~m}(46 \mathrm{ft})$. The hanger had concrete block walls to a height of $11.0 \mathrm{~m}(36.5 \mathrm{ft})$, with the upper walls of steel panel construction. The roof was supported with open steel trusses spanning the full width of the building. The flat ceiling was composed of corrugated steel panels with $38 \mathrm{~mm}$ (1.5 in) deep corrugations supported on, and perpendicular to, $254 \mathrm{~mm}$ (10 in) deep steel I beams installed on $2.0 \mathrm{~m}$ ( $6 \mathrm{ft}-8 \mathrm{in})$ centers perpendicular to and on top of the trusses. The location of the ceiling beams near the fire area is shown in figure 1 . These beams extended the full length and width of the hanger bay. The hanger bay had two rolling steel overhead doors to the outside which were closed during the tests. In addition there were a number of passageway doors to both the outside and to other parts of the building. Although some of these doors were open during the tests, they had no observable impact on the measurements. Ventilation fans with automatic louvers were located in the walls of the main hanger bay. These fans were off and the louvers closed during the tests. The hanger bay was fully sprinklered with extra high tempcraturc upright sprinklers.

The fuel for the test fires was industrial grade isopropyl alcohol. The alcohol was placed in 4 steel pans each measuring 0.9 by $0.9 \mathrm{~m}$ ( 3 by $3 \mathrm{ft}$ ) and $25 \mathrm{~mm}(1 \mathrm{in})$ deep. The pans were placed together to form a square fire area 1.8 by $1.8 \mathrm{~m}$ (6 by $6 \mathrm{ft}$ ). The pans were supported on 2 bricks approximately $125 \mathrm{~mm}$ ( 5 in) above the floor. The location of the pans is shown in figure 1 . The quantity of alcohol used in the tests was not measured but the pans were filled to a depth of approximately $13 \mathrm{~mm}(0.5 \mathrm{in})$ which provided adequate fuel for the test duration. The alcohol was ignited with a match and the fire was extinguished with carbon dioxide extinguishers approximately 60 seconds after ignition.

The instrumentation consisted of $0.05 \mathrm{~mm}$ (0.02 in) diameter bare-bead chromel-alumel thermocouples and $9.75 \mathrm{~mm}$ ( $0.384 \mathrm{in})$ diameter, $2.3 \mathrm{~mm}$ (0.092 in) thick brass disks attached to thermocouples. The brass disks were used to simulate the heat responsive element in a sprinkler. Thermocouples were located above the center of the test pan 5.2, 8.2, and $11.3 \mathrm{~m}(17,27$, and $37 \mathrm{ft})$ above the floor. A thermocouple and disk were positioned $380 \mathrm{~mm}$ (15 in) below the ceiling at distances of $0,2.7,5.5,8.2$, and $11.0 \mathrm{~m}$ $(0,9,18,27$, and $36 \mathrm{ft})$ radially from the center of the pan. The disks were oriented with the flat face perpendicular to the ceiling and normal to a radial line from the centerline of the fire. At a radial distance

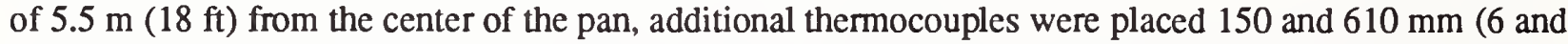

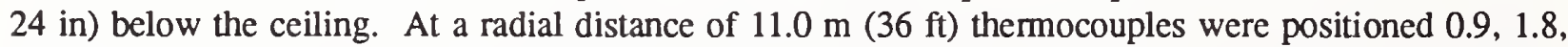
$3.4,4.9,6.4,7.9$, and $9.4 \mathrm{~m}(3,6,11,15,21,26$, and $31 \mathrm{ft})$ below the ceiling. The ceiling jet flow from the fire past the thermocouples and disks was in the direction of the corrugations in the ceiling panels and perpendicular to the $254 \mathrm{~mm}$ (10 in) I beams supporting the ceiling. The temperatures of the bare-bead thermocouples and the brass disks were recorded every 1.3 seconds on a computer based data acquisition system. The resolution of the data acquisition system was $0.3^{\circ} \mathrm{C}$ and the thermocouple error was $\pm 2.2^{\circ} \mathrm{C}$.

Two quick response sprinklers, one with a temperature rating of $74^{\circ} \mathrm{C}\left(165^{\circ} \mathrm{F}\right)$ and one with a temperature rating of $100^{\circ} \mathrm{C}\left(212^{\circ} \mathrm{F}\right)$, were located above the center of the pan $380 \mathrm{~mm}$ (15 in) below the ceiling. These sprinklers were not connected to a piping system but were electrically monitored to determine the time of operation. 


\subsection{HEAT RELEASE RATE}

The heat release rate of the isopropyl alcohol fire was determined by conducting experiments in a fire test facility utilizing a set of four pans with the same fire area as those used in the aircraft hanger. The heat release rate tests, using oxygen consumption calorimetry, were conducted under a large exhaust collection hood. A discussion of the principles of oxygen consumption calorimetry can be found in reference [7]. To summarize the method of oxygen consumption calorimetry, all of the gaseous combustion products from the buming fuel flow through a duct where the mass flow rate and oxygen concentration are measured as a function of time. From these measurements the rate at which oxygen is consumed by the fire in the combustion process can be determined. For most common fuels the rate of heat release is proportional to the rate of oxygen consumption regardless of the fuel burned. In the isopropyl alcohol tests the data collection and processing was computerized with measurements taken every 5 seconds.

Two tests with the same quantity of fuel were conducted, resulting in measured peak heat release rates of 3900 and $3400 \mathrm{~kW}$. The variation in the test results was due in part to warping of the fuel pans during the test with the lower heat release rate and in part to the estimated $\pm 10 \%$ variability in large scale calorimeter measurements. When the pans warped, the fuel was concentrated in some areas, leaving no fuel in other areas. Warping of the pans may have taken place in the tests conducted in the aircraft hanger. Since the heat release rate in the aircraft hanger could not be measured directly, the two measured heat release rates along with an average value of $3650 \mathrm{~kW}$ were examined as candidates for the $3.34 \mathrm{~m}^{2}$ $\left(36 \mathrm{ft}^{2}\right.$ ) isopropyl alcohol fire. No values for the heat release rate or buming rate of isopropyl alcohol could be found in the literature.

Although the heat release rate in the hanger could not be measured directly, the measured centerline plume temperature and calculated velocity could be compared to predictions of these parameters based on the heat release rate. These predictions are not completely independent of the calculation of thermal device response, since both DETACT-QS and LAVENT utilize predictions of ceiling jet temperature and velocity based on the heat release rate and other factors. The comparison of measured and predicted values in the plume yields only an approximate check of the heat release rate. The heat release rate raised to a fractional power appears in all of the predictions, and as a result, the predicted plume values are only weakly dependent on the heat release rate of the fire.

There are a number of prediction methods available in the literature for plume temperature and velocity. Prediction methods have been proposed for different fire regimes and diameters, but in general, over their range of applicability, the different methods produce very similar results. For the comparisons performed here the prediction methods of Heskestad were selected[8]. The expressions for the plume centerline temperature rise, velocity, radius and virtual origin are:

$$
\Delta T_{0}=9.1\left(\frac{T_{\infty}}{g_{p} C_{p}^{2} \rho_{\infty}^{2}}\right)^{1 / 3} Q_{c}^{2 / 3}\left(z-z_{0}\right)^{-5 / 3}
$$




$$
\begin{gathered}
u_{0}=3.4\left(\frac{g}{C_{p} \rho_{\infty} T_{\infty}}\right)^{1 / 3} Q_{c}^{1 / 3}\left(z-z_{0}\right)^{-1 / 3} \\
b_{\Delta T}=0.12\left(\frac{T_{0}}{T_{\infty}}\right)^{1 / 2}\left(z-z_{0}\right) \\
z_{0}=-1.02 \mathrm{D}+0.083 \mathrm{Q}^{2 / 5}
\end{gathered}
$$

where:

$\Delta \mathrm{T}_{0}=$ centerline temperature rise above ambient (K)

$\mathrm{u}_{0}=$ centerline velocity $\left(\mathrm{m} / \mathrm{s}^{2}\right)$

$\mathrm{b}_{\Delta \mathrm{T}}=$ plume radius where $\Delta \mathrm{T}=0.5 \Delta \mathrm{T}_{0}(\mathrm{~m})$

$\mathrm{z}_{0}=$ elevation of the virtual origin above the fire source $(\mathrm{m})$

$\mathrm{T}_{\infty}=$ ambient temperature $(\mathrm{K})$

$\mathrm{T}_{0}=$ center temperature $(\mathrm{K})$

$\mathrm{g}=$ acceleration due to gravity $\left(\mathrm{m} / \mathrm{s}^{2}\right)$

$\mathrm{C}_{\mathrm{p}}=$ constant pressure specific heat of air $(\mathrm{kJ} / \mathrm{kg} \mathrm{K})$

$\rho_{\infty}=$ density of air $\left(\mathrm{kg} / \mathrm{m}^{3}\right)$

$\mathrm{Q}_{\mathrm{c}}=$ convective heat release rate $(\mathrm{kW})$

$\mathrm{D}=$ fire diameter $(\mathrm{m})$

$\mathrm{z}=$ elevation above the fire source $(\mathrm{m})$

The expressions for plume temperature and velocity are based on the convective heat release rate. The convective heat release rate is the enthalpy from the fire transported to the plume by convective transport and does not include the enthalpy radiated from the flaming region. For many common fuels with luminous flames it has been found that the convective heat release rate is approximately $65 \%$ of the total heat release rate[9]. Although many alcohols burn without luminous flames, isopropyl alcohol flames are very luminous appearing much like the flames from burning heptane. Since there have been no measurements for isopropyl alcohol, the typical value of $65 \%$ was used.

The plume expressions are based on a point source fire. Since real fires have a finite area source, a virtual origin is used to represent the fire to be analyzed. The virtual origin is the location, above the buming fuel surface, of a point source fire which is equivalent to the actual finite area fire. The virtual origin is usually near the fuel surface and is frequently considered to be located on the surface for predictions at high elevations. The fire diameter used in the calculations was based on a circle with the same area as the square test pans.

Using the values of $T_{\infty}=296 \mathrm{~K}, \mathrm{~g}=9.8 \mathrm{~m} / \mathrm{s}^{2}, \mathrm{C}_{\mathrm{p}}=1.0 \mathrm{~kJ} / \mathrm{kg} \mathrm{K}, \rho_{\infty}=1.2 \mathrm{~kg} / \mathrm{m}^{3}, \mathrm{D}=2.1 \mathrm{~m}, \mathrm{Q}=3900$, 3650 , and $3400 \mathrm{~kW}$, and $\mathrm{Q}_{\mathrm{c}}=2535,2373$, and $2210 \mathrm{~kW}$ the centerline plume temperatures, velocity and radius were calculated at distances of 5.2, 8.2, 11.3, and $14 \mathrm{~m}(17,27,37$, and $46 \mathrm{ft})$ above the fire. Table 1 shows the predicted plume properties and table 2 gives the measured maximum plume centerline 
temperatures. The measured temperatures have not been corrected for the thermal radiation gain form the flames and the loss to the surroundings. A steady-state approximation of the net radiation effect shows the thermocouples over the fire near the ceiling would indicate a temperature less than $0.2^{\circ} \mathrm{C}$ higher than the true gas temperature. This is well within the accuracy of the thermocouples and the data acquisition system. The thermocouple at a distance of $5.2 \mathrm{~m}(17 \mathrm{ft})$ above the fire may indicate a temperature $10^{\circ} \mathrm{C}$ or more above the true gas temperature and is less reliable for comparison purposes. This correction is much less certain due to the fluctuation in flame height, which was observed to be on the order of $3 \mathrm{~m}$ ( $9 \mathrm{ft}$ ), the assumed radiative fraction, the turbulent nature of the fire plume, and the steady-state approximation.

An examination of the centerline plume temperatures indicates that the measurements from test 1 most closely match the predictions for a $3900 \mathrm{~kW}$ fire and the measurements from test 2 most closely match the predictions for a $3650 \mathrm{~kW}$ fire although the differences in all cases were relatively small. The temperature measurements at $14 \mathrm{~m}(45 \mathrm{ft})$ have been included here for comparison even though the thermocouples were within $380 \mathrm{~mm}$ (15 in) of the ceiling. Due to the plume impacting the ceiling near these thermocouples they are probably within the ceiling jet and will be evaluated in detail in the next section.

There were no direct measurements of plume velocity made during these experiments. In some cases it is possible to estimate the plume velocity from thermocouple measurements by measuring the time required for hot gas to pass individual thermocouples a known distance apart. The predicted maximum velocities of 6 to $8 \mathrm{~m} / \mathrm{s}$ were beyond the measurement resolution based on the thermocouple spacing and the data acquisition speed.

As will be shown in a later section, the ceiling thermocouples at the centerline and at a radial distance of $2.7 \mathrm{~m}$ both began to respond to the plume at the same time but the thermocouple at $5.5 \mathrm{~m}$ did not. This would indicate a plume radius between 2.7 and $5.5 \mathrm{~m}(9$ and $18 \mathrm{ft})$ when the plume reached the ceiling. This agrees with the prediction of $3.2 \mathrm{~m}$ for all of the heat release rates since the predicted plume radius is not affected by the change in heat release rate over the range examined.

Since the temperature measurements for the two hanger tests are essentially similar only the results from the second test will be presented. A maximum estimated heat release rate of $3650 \mathrm{~kW}$ will be used since there was slightly better agreement between the predicted and measured plume temperatures with that heat release rate. The variation of $\pm 7 \%$ between the average heat release rate of $3650 \mathrm{~kW}$ and the low of 3400 and high of $3900 \mathrm{~kW}$ is within the accuracy of expected for large scale calorimeter measurements.

\subsection{FIRE MODEL DATA}

The data input requirements for the two computer models, DETACT-QS and LAVENT, differ in detail and form. Both require a description of the fire, and for this analysis, the fire was characterized by the heat release rate as a function of time. An initial growth phase for the fire was selected to provide a reasonable fit with the measured temperature rise early in the fire. Since the results from both models either reach or approach steady state, this early growth does not have a significant impact on the final predicted values. The values for the heat release rate used are shown in table 3. Both DETACT-QS and LAVENT perform a linear interpolation to determine the heat release rate at intermediate times as required. 
The data used in DETACT-QS is shown in table 4 and the data for LAVENT in table 5. A device activation temperature of 999 was used for both models since the predicted thermal device temperature was compared to the measured temperature of the disk and not to the activation time of a sprinkler or detector. The exact composition of the ceiling in the hanger is unknown. For the $60 \mathrm{~s}$ test duration, the majority of the heat transfer took place to the steel underside of the roof deck; thus the thermal properties for steel have been used. Example runs with LAVENT showed the results were not sensitive to the ceiling thermal properties or the number of ceiling grid points for these short duration fires.

LAVENT is a unique zone model in that it utilizes draft curtains instead of walls. Draft curtains are partitions extending below the ceiling which are designed to restrict the rapid spread of hot fire gases across the ceiling. The concentration of hot fire gases speeds the operation of sprinklers and reduces the likelihood of unwanted sprinkler operation far from the fire. In addition, draft curtains may be used to concentrate the hot fire gases in the vicinity of a ceiling vent. LAVENT assumes the space under consideration is very large and the walls are of sufficient distance from the fire that a hot upper layer does not accumulate in the entire building over the time of the analysis. A hot upper layer may accumulate within the area confined by the draft curtains. If the interface between the hot upper layer and the ambient lower layer descends to a position below the bottom of the draft curtains, hot gasses flow past the bottom of the draft curtains into the rest of the building.

For buildings with no draft curtains, the walls may be simulated by draft curtains which extend to the floor. This results in the growth of a hot upper layer over the entire area of the building, and LAVENT accounts for the contribution hot gas in the upper layer to the fire plume. This approximation is appropriate until the interface between the hot upper layer and the lower layer nears the floor. If the height of the base of the draft curtains is specified to be equal to the ceiling height then a hot upper layer will never accumulate in the building regardless of the floor area specified.

Two sets of predictions were made with LAVENT. In the first case a height of the base of the draft curtain above the floor of $0 \mathrm{~m}(0 \mathrm{ft})$ was used. This corresponds to a draft curtain extending all the way to the floor which is used in this case to represent the walls. This will be referred to as the confined case since a hot layer develops in the compartment and influences the ceiling jet. In the second case a height

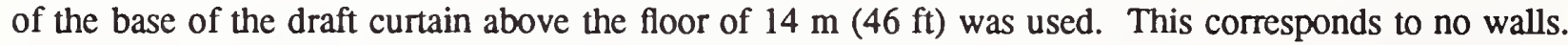
This will be referred to as the unconfined case since no hot layer develops and ceiling jet predictions should be similar to those from DETACT-QS.

\subsection{COMPARISON OF PREDICTED AND MEASURED CEILING JET TEMPERATURES}

Figures 2 through 6 show the measured and predicted ceiling jet (gas) and disk temperatures at radial distances of $0,2.7,5.5,8.2$, and $11.0 \mathrm{~m}(0,9,18,27$ and $36 \mathrm{ft})$ from the centerline of the fire. These radial distances correspond to nondimensional radii $(r / h)$ of $0,0.19,0.39,0.59$, and 0.79 . The nondimensional radius is defined as the radial distance from the centerline of the fire to the thermal device, divided by the distance from the top of the fuel to the ceiling. The expressions for ceiling jet temperature and velocity in both DETACT-QS and LAVENT, are expressed as functions of the nondimensional radius. Each of the figures shows the measured gas jet and disk temperatures as solid lines. In figure 3, the disk at a radial distance of $2.7 \mathrm{~m}(9 \mathrm{ft})$ malfunctioned, and the data are not shown. The DETACT-QS predictions for gas and jet temperatures are shown as dashed lines. Each figure shows the confined and unconfined LAVENT predictions for both the gas and disk temperatures. The predicted gas jet and disk temperatures along with the jet velocities at the end of the 60 second simulation for all three cases are shown in table 6. 
Figure 2 shows the measurements and predictions at a radial distance of $0 \mathrm{~m}(0 \mathrm{ft})$. The DETACT-QS ceiling jet prediction is very close to the measured value, although DETACT-QS predicts a slightly higher disk temperature than was measured after approximately 25 seconds. This may be a result of the ceiling jet flow at the centerline of the fire being nearly parallel to the flat face of the disk. As the ceiling jet becomes well established away from the centerline of the fire, the flow should be nearly normal to the flat face of the disk. The RTI measurements for the disks were made with the flow normal to the flat face. Both the confined and unconfined LAVENT predictions are substantially lower than the measurements. The two quick response sprinklers, one with a temperature rating of $74^{\circ} \mathrm{C}\left(165^{\circ} \mathrm{F}\right)$ and one with a temperature rating of $100^{\circ} \mathrm{C}\left(212^{\circ} \mathrm{F}\right)$ located adjacent to the thermocouple and disk at a radial distance of $0 \mathrm{~m}(0 \mathrm{ft})$ did not operate during or after the test. This result is consistent with the measured temperatures which were generally less than $70^{\circ} \mathrm{C}\left(158^{\circ} \mathrm{F}\right)$.

Figure 3 shows the measurements and predictions at a radial distance of $2.7 \mathrm{~m}(9 \mathrm{ft})$ or an $\mathrm{r} / \mathrm{h}$ of 0.19 . At this distance DETACT-QS predicts a higher gas temperature than was measured, the LAVENT confined prediction is very close to the gas temperature and the LAVENT unconfined prediction is less than the measurement. It can be seen that the LAVENT predictions are the same for an $\mathrm{r} / \mathrm{h}$ of 0 and 0.19 . The expressions for ceiling jet temperature and velocity used in LAVENT are independent of radius for $\mathrm{r} / \mathrm{h}<0.2$ and equal to the values obtained when $\mathrm{r} / \mathrm{h}=0.2$. The expressions used in DETACT-QS for jet temperature and velocity are independent of radius for $\mathrm{r} / \mathrm{h} \leq 0.18$. The independence of temperature and velocity for small $\mathrm{r} / \mathrm{h}$ in both models is used to represent the regime in which the flow from the plume dominates. The temperature data in this case indicates a dependence on radius within the plume impingement zone.

Figures 4 through 6 show the measurements and predictions at radial distance of 5.5, 8.2 and $11.0 \mathrm{~m}$ (18, 27 , and $36 \mathrm{ft}$ ). The results shown in all three figures are similar, with good agreement between the measured gas temperatures and the predictions of DETACT-QS and LAVENT (unconfined). LAVENT (confined) predicts a substantially higher jet temperature and thus a higher disk temperature. The high ceiling jet temperature in the confined case is a result of the high predicted average upper layer temperature.

\subsection{Upper Layer Growth}

The upper layer temperature predicted by LAVENT was compared to the upper layer temperature predicted by ASET-B. ASET-B is a single compartment computer fire model written by Walton and based on expressions developed by Cooper[10]. Unlike LAVENT, ASET-B does not calculate heat transfer to the ceiling; instead, the user specifies a fraction of the heat released by the fire which will be lost to the contents and bounding surfaces of the compartment. Experience has shown that heat loss fractions of 0.6-0.9 usually result in reasonable agreement between measured and predicted upper layer temperatures[11].

The average upper layer temperatures predicted by LAVENT (confined) are shown in figure 7. Also shown in figure 7 is the average upper layer temperature predicted by ASET-B for heat loss fractions of $0.5,0.7$, and 0.9 , and the predicted height of the interface between the upper and lower layers. The same interface face height was predicted by both LAVENT and ASET-B and is shown in the figure as a percentage of ceiling height. Figure 7 shows that the predictions of ASET-B agree with those from LAVENT when the ASET-B heat loss fraction is approximately 0.5 . Also shown in figure 7 is the

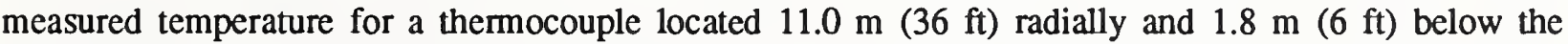
ceiling. This corresponds to $87 \%$ of the ceiling height. The thermocouple at this location responds to an 
increase in temperature at nearly the same time ASET-B and LAVENT predict the layer interface would reach that point. The thermocouple at the same radial distance but at $76 \%$ of the ceiling height did not respond to a temperature rise during the 60 second test. This may indicate that the models have accurately predicted the arrival of the interface, or alternatively the measured temperature increase may be the result of the ceiling jet reflecting off the wall of the hanger and returning under the main ceiling jet towards the fire. The lack of additional instrumentation makes it impossible to determine if the assumption of a uniform hot upper layer over the entire hanger bay is reasonable.

The temperature measured by the thermocouple at $87 \%$ of the ceiling height is nearly equal to the value predicted by ASET-B with a heat loss fraction of 0.7 . If a layer did exist over the entire hanger bay it is unlikely its temperature would be completely uniform and likely be lower in areas farther from the fire. From the temperature measurements and the supporting predictions of ASET-B it would appear that in the confined case LAVENT underpredicts the heat transfer resulting in higher upper layer temperatures than would be expected. These high upper layer temperatures then lead to high thermal device temperatures. Zones models generally do not include the transport time between the fire region and the ceiling and assume that the heat released by the fire immediately reaches the upper layer. This approximation becomes less accurate as the ceiling height increases.

\subsection{Hot Gas Transport Time}

The measured gas disk temperatures shown in figures 2 through 6 show an increasing time offset with increasing radial distance from the centerline of the fire. Figure 8 shows the measured gas temperatures

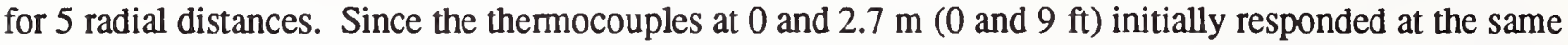
time, the plume reaches these thermocouples at the same time. The calculated plume radius shown in table 1 for all of the steady fire sizes is $3.2 \mathrm{~m}(10.5 \mathrm{ft})$, which agrees with this result.

From figure 8 it can be seen that the thermocouples at 0 and $2.7 \mathrm{~m}(0$ and $9 \mathrm{ft}$ ) responded at approximately 4.5 seconds, and the thermocouples at $5.5,8.2$ and $11.0 \mathrm{~m}(18,27$ and $36 \mathrm{ft})$ at 8,15 and 18 seconds respectively. These distances and times yield local radial gas velocities ranging from 0.4 to $0.9 \mathrm{~m} / \mathrm{s}$. These velocities are much lower than the values predicted by both DETACT-QS and LAVENT as shown in table 6 . The difference between the predicted and estimated velocities may be a result of the $254 \mathrm{~mm}$ (10 in) deep beams supporting the ceiling perpendicular to the direction of the ceiling jet flow. The expressions for thermal device heating used in both DETACT-QS and LAVENT assume the ceiling is smooth and neither model accounts for the transport time of hot gas from the fire to the device.

Figure 9 shows the predicted gas and disk temperature from DETACT-QS at a radial distance of $11.0 \mathrm{~m}$ (36 ft). Also shown in the figure are the same gas and disk temperature predictions shifted 14 seconds to the right. The 14 second shift was selected to match the times of the predicted gas and disk temperature rises to the times of measured temperature rises. DETACT-QS does not account for the transport time in the plume so changes in the input fire immediately affect the predicted temperatures at the ceiling. In this case the transport time from the fire to the a radial distance of $11.0 \mathrm{~m}$ ( $36 \mathrm{ft}$ ) is approximately 14 seconds. A similar correction could be applied to the LAVENT results.

\subsection{Distance of Thermal Device Below the Ceiling}

The correlations on which DETACT-QS is based assume the thermal device is located not only on a smooth ceiling, but at the point of maximum temperature and velocity. Alpert reports that when there is no accumulation of hot gasses the maximum temperature occurs at a distance below the ceiling of no more 
than 1 percent of the total ceiling height. Alpert also indicates that limited data suggest the maximum gas velocity occurs at approximately the same distance below the ceiling as the maximum temperature. Further, for both temperature and gas velocity outside the plume region, the lower edge of the ceiling jet is located from 5.5 to 12 percent of the total ceiling height below the ceiling. Alpert speculates that beams protruding less than 1 percent of the total ceiling height will not "disturb" the flow and in these cases the

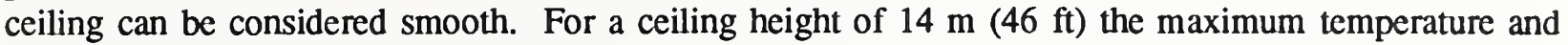
velocity would be estimated to occur at a distance of $140 \mathrm{~mm}$ (5.5 in) below the ceiling and beams with depths of less than $140 \mathrm{~mm}$ (5.5 in) would not substantially alter the flow. Therefore for the tests in the hanger, the $254 \mathrm{~mm}$ (10 in) beams would have likely influenced the temperature and velocity distributions.

LAVENT predicts a temperature and velocity profile for the ceiling jet which, at the ceiling, begins at the ceiling temperature and zero velocity and reaches a point of maximum temperature and velocity at a distance $0.23 \delta$ below the ceiling where $\delta / \mathrm{h}=0.10(\mathrm{r} / \mathrm{h})^{0.9}$. For radial distances of $2.7,5.5,8.2$, and $11.0 \mathrm{~m}(9,18,27$ and $36 \mathrm{ft})$ the maximum temperature and velocity predicted by LAVENT occurs at a distance below the ceiling of $0.5,1.0,1.5$ and 2.0 percent of the ceiling height respectively.

Figure 10 shows measurements and predictions at a radial distance of $5.5 \mathrm{~m}$ (18 ft) corresponding to an $\mathrm{r} / \mathrm{h}$ of 0.39 . Measurements are shown for three thermocouples at distances of 150,380 , and $610 \mathrm{~mm}(6$, 15 , and $24 \mathrm{in)}$ below the ceiling. Also shown in figure 10 are the predictions from LAVENT, both confined and unconfined, for the same distances below the ceiling. The measured temperatures are slightly higher closer to the ceiling but the variation with distance is substantially less than the LAVENT predictions. This may be due to the mixing caused by the ceiling jet passing over the beams and the presence of a beam very near the thermocouples.

\subsection{SENSITIVITY OF MODEL PREDICTIONS TO HEAT RELEASE AND RTI INPUTS}

The input values of heat release rate and disk RTI, while based on measurement, are subject to a degree of uncertainty. In engineering application of models such as DETACT-QS and LAVENT the chosen heat release is assumed to characterize a given hazard. In order to examine the effect of heat release rate and disk RTI, DETACT-QS was exercised with; 1) a heat release rate of plus and minus 20 percent of the value thought to best match the test conditions, and 2) an RTI of plus and minus 20 percent of the measured RTI for the disk. A heat release rate of plus and minus 20 percent represents an uncertainty of twice that expected for calorimeter measurements. Although an error analysis for RTI measurements of thermal devices could not be found in the literature, an RTI of plus and minus 20 percent is more than twice the uncertainty that would be expected.

Figure 11 shows the measurements at a radial distance of $5.5 \mathrm{~m}(18 \mathrm{ft})$ and the predictions from DETACT-QS using a heat release rate of plus and minus 20 percent of the values given in table 3 . The average fluctuation in the measured temperature is approximately one half the change in the predicted temperature resulting from an input heat release rate of minus 20 percent to plus 20 percent. At the end of the 60 second simulation the change in the predicted disk temperature resulting from a change in the input heat release rate from minus 20 percent to plus 20 percent has grown to almost equal the change in the predicted gas temperature.

Figure 12 shows the measurements at a radial distance of $5.5 \mathrm{~m}(18 \mathrm{ft})$ and the predictions from DETACT-QS using an RTI of plus and minus 20 percent of the RTI measured for the brass disks which was $57.7(\mathrm{~m} \mathrm{~s})^{-12}$. A change in the input disk RTI results only in a change in the predicted disk temperature and not in the predicted gas temperature. The average fluctuation in the measured disk 
temperature is approximately equal to the change resulting from an input RTI from minus 20 percent to plus 20 percent of the measured value for the disk.

These results show that the predictions are more sensitive to changes in the input heat release rate than to the input RTI. The measurements of the gas and disk temperatures fluctuated over a range corresponding to a change in the input heat release rate of approximately plus and minus 10 percent. The fluctuation was most likely caused by the turbulence created by the non-smooth ceiling. There was a plus and minus 7 percent change in the predicted gas and disk temperatures resulting from a change in the input heat release rate of plus and minus 20 percent at a radial distance of $5.5 \mathrm{~m}(18 \mathrm{ft})$. The change in predicted gas and disk temperatures was plus and minus 9 percent at a radial distance of $0 \mathrm{~m}(0 \mathrm{ft})$ and 5 percent at a radial distance of $11.0 \mathrm{~m}$ ( $36 \mathrm{ft})$. A change in the input RTI of plus and minus 20 percent would result in a change in the predicted disk temperature of minus and plus 4 percent for all radial distances. While an error of plus or minus 20 percent in the chosen heat release rate would change both the DETACT-QS and LAVENT predictions, it would not change the conclusions drawn in this study. If both the heat release rate and RTI were in error by 20 percent in the direction to cause the maximum change in the disk temperature, the change would range from plus and minus 13 percent at a radial distance of $0 \mathrm{~m}(0 \mathrm{ft})$ to 9 percent at a radial distance of $11 \mathrm{~m}(36 \mathrm{ft})$. Although the agreement between measured and predicted disk temperatures would be less satisfactory, even this combined error would not change the conclusions drawn in this study.

\subsection{SUMMARY AND CONCLUSIONS}

The applicability of DETACT-QS and LAVENT to relatively large building spaces with high ceilings has been examined with a limited set of test data. Although the results do not necessarily apply to other uses of the models they do provide a degree of insight into the application of the models to actual buildings.

Both DETACT-QS and LAVENT demonstrated the capability to predict thermal device temperatures in large, high ceiling space buildings. Although the model predictions were compared to idealized thermal devices in the form of brass disks, it is expected that similar results would be obtained with sprinkler or detectors. For the building and fire under consideration, the development of a hot upper layer did not seem to have a significant impact on the temperature in the ceiling jet. As a result, both DETACT-QS and LAVENT (unconfined) provided good predictions for $\mathrm{r} / \mathrm{h}$ greater than 0.2 , although neither account for gas transport time. The failure to account for gas transport time in this large space would result in the measured time for device actuation being significantly longer than would be predicted. For $\mathrm{r} / \mathrm{h}<0.2$ DETACT-QS provided better predictions than LAVENT (unconfined) which underpredicted the temperatures. LAVENT (confined) provided better predictions than LAVENT (unconfined) case for $\mathrm{r} / \mathrm{h}<0.2$ but substantially overpredicted the gas and disk temperatures for $\mathrm{r} / \mathrm{h}>0.2$. The overpredictions in the confined case may be due to the lack of gas transport time in the layer calculation. This would result in a device taking longer to operate than predicted.

LAVENT did not accurately predict the temperature profile as a function of distance below the ceiling for the single radial distance at which measurements were made. LAVENT predicted a wider variation in temperatures than were measured. This may be a result of the non-smooth nature of the ceiling in the hanger and a beam near the measurement point.

Based on the limited comparisons examined here it appears that for large building spaces, with ceiling heights on the order of $15 \mathrm{~m}(50 \mathrm{ft})$ and steady fires on the order of $4 \mathrm{MW}$, that DETACT-QS and LAVENT in the unconfined mode provided reasonable predictions of ceiling jet temperatures and 
somewhat conservative predictions for thermal device temperatures. LAVENT did not provide a good prediction of the temperature profile below the ceiling and, in the confined mode, overpredicted the upper layer and thermal device temperature.

\subsection{ACKNOWLEDGEMENTS}

Appreciation is extended to the National Fire Sprinkler Association for arranging access to the fire tests through the sprinkler contractor. Appreciation is also extended to J. McElroy, D. Madrzykowski, R. Lawson, and D. Evans of the Building and Fire Research Laboratory for assistance in conducting the tests.

\subsection{REFERENCES}

1. Heskestad, G. and Bill Jr., R.G., Quantification of Thermal Responsiveness of Automatic Sprinklers Including Conduction Effects. Fire Safety Jour. 14(1 \& 2): 113-125; 1988 July.

2. Schifiliti, R.P., Design of Detection Systems, section 3 chapter 1 in SFPE Handbook of Fire Protection Engineering. Boston, MA: National Fire Protection Association; 1988. 3-1-3-21.

3. Alpert, R.L., Calculation of the Response Time of Ceiling-Mounted Fire Detectors. Fire Tech. 8(3): 181-195; 1972 Aug.

4. Evans, D.D. and Stroup, D.W., Methods to Calculate the Response time of Heat and Smoke Detectors Installed Below Large Unobstructed Ceilings. Fire Tech. 22(1): 54-65; 1986 Feb.

5. Cooper, L.Y., Estimating the Environment and the Response of Sprinkler Links in Compartment Fires with Draft Curtains and Fusible Link-Actuated Ceiling Vents-Theory. Fire Safety Jour. 16: 137-163; 1990.

6. Davis W.D. and Cooper, L.Y., Estimating the Environment and the Response of Sprinkler Links in Compartment Fires with Draft Curtains and Fusible Link-Actuated Ceiling Vents. Fire Tech. 27(2): 113127; 1991 May.

7. Janssens, M.L., Measuring Rate of Heat Release by Oxygen Consumption. Fire Tech. 27(3): 234-249; Aug 1991.

8. Heskestad, G., Fire Plumes, section 1 chapter 6 in SFPE Handbook of Fire Protection Engineering. Boston, MA: National Fire Protection Association; 1988. 1-107-1-115.

9. Mudan, K.S. and Croce, P.A., Fire Hazard Calculations for Large Open Hydrocarbon Fires, section 2 chapter 4 in SFPE Handbook of Fire Protection Engineering. Boston, MA: National Fire Protection Association; 1988. 2-54.

10. Walton, W.D., ASET-B: A Room Fire Program for Personal Computers. Fire Tech. 21(4): 293-309; 1985 Nov.

11. Cooper, L.Y., A Mathematical Model for Estimating Available Safe Egress Time in Fires. Fire and Mat. 6(3\&4): 135-144, 1982 Sept/Dec. 
Table 1. Predicted plume properties

\begin{tabular}{cccccc}
$\mathbf{Q}(\mathbf{k W})$ & $\mathbf{Q}_{c}(\mathbf{k W})$ & $\mathbf{z}(\mathbf{m})$ & $\mathrm{T}_{0}\left({ }^{\circ} \mathrm{C}\right)$ & $\mathbf{u}_{0}(\mathrm{~m} / \mathbf{s})$ & $\mathbf{b}_{\Delta \mathrm{T}}(\mathbf{m})$ \\
\hline \multirow{2}{*}{3900} & 2535 & 5.2 & 334 & 8.2 & 1.5 \\
& & 8.2 & 167 & 7.0 & 2.1 \\
& 11.3 & 107 & 6.3 & 2.7 \\
& & 14.0 & 81 & 5.8 & 3.2 \\
\hline \multirow{2}{*}{3650} & 2373 & 5.2 & 315 & 7.9 & 1.5 \\
& & 8.2 & 159 & 6.8 & 2.1 \\
& & 11.3 & 102 & 6.1 & 2.7 \\
\multirow{2}{*}{3400} & 14.0 & 78 & 5.7 & 3.2 \\
\hline \multirow{2}{*}{2210} & 5.2 & 273 & 7.7 & 1.5 \\
& & 8.2 & 151 & 6.6 & 2.1 \\
& & 11.3 & 98 & 6.0 & 2.7 \\
& & 14.0 & 75 & 5.6 & 3.2
\end{tabular}

Table 2. Maximum measured plume temperatures

$\begin{array}{ccc}\mathbf{z}(\mathrm{m}) & \mathrm{T}_{\mathbf{0}}\left({ }^{\circ} \mathrm{C}\right)-\text { Test } \mathbf{1} & \mathrm{T}_{\mathbf{0}}\left({ }^{\circ} \mathrm{C}\right)-\text { Test } 2 \\ 5.2 & 420 & 320 \\ 8.2 & 165 & 150 \\ 11.3 & 105 & 100 \\ 14.0 & 86 & 82\end{array}$


Table 3. Input heat release rate

$\begin{array}{cc}\text { Time (s) } & \begin{array}{c}\text { Heat Release } \\ \text { Rate (kW) }\end{array} \\ 0 & 0 \\ 5 & 385 \\ 10 & 1750 \\ 15 & 3650 \\ 60 & 3650\end{array}$

Table 4. DETACT-QS input values

Height of ceiling above fuel

Distance of detector from axis of fire

Initial room temperature

Detector actuation temperature

Detector RTI
$14.0 \mathrm{~m}$

$0.0,2.7,5.5,8.2$, and $11.0 \mathrm{~m}$

$23^{\circ} \mathrm{C}$

$999^{\circ} \mathrm{C}$

$57.7\left(\mathrm{~m} \mathrm{~s}^{-1 / 2}\right.$ 
Table 5. LAVENT input values

Ceiling height

Room length

Room width

Number of vents

Curtain length

Height to bottom of curtain

Ambient temperature

Ceiling thermal conductivity

Ceiling density

Ceiling heat capacity

Ceiling thickness

Fuel height

Fuel diameter

Link radial distance

Link distance below ceiling

Link RTI

Link fuse temperature

Gauss-Seidel relaxation

Differential equation solver tolerance

Flux update interval

Number of ceiling grid points

Solver type

Smallest meaningful value
$14.0 \mathrm{~m}$

$37.2 \mathrm{~m}$

$40.2 \mathrm{~m}$

0

$154.8 \mathrm{~m}$

$0 \mathrm{~m}$ (confined) and $14.0 \mathrm{~m}$ (unconfined)

$296 \mathrm{~K}$

$45.8 \mathrm{~W} / \mathrm{m} \mathrm{K}$

$7850 \mathrm{~kg} / \mathrm{m}^{3}$

$460 \mathrm{~J} / \mathrm{m} \mathrm{K}$

$0.1 \mathrm{~m}$

$0 \mathrm{~m}$

$2.1 \mathrm{~m}$

$0.0,2.7,5.5,8.2$, and $11.0 \mathrm{~m}$

$0.15,0.38$, and $0.61 \mathrm{~m}$

$57.7\left(\mathrm{~m} \mathrm{~s}^{-1 / 2}\right.$

$999 \mathrm{~K}$

0.65

0.00001

$2.0 \mathrm{~s}$

6

non-stiff

$0.1 \times 10^{-7}$ 


$$
\begin{aligned}
& \text { 产离 }
\end{aligned}
$$

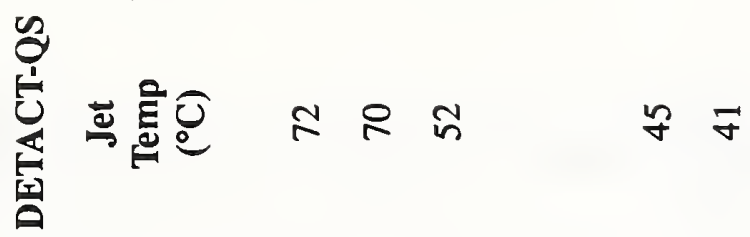

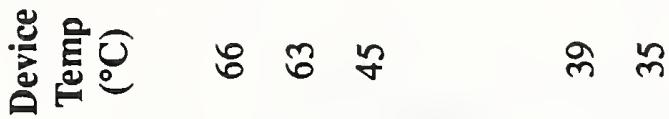

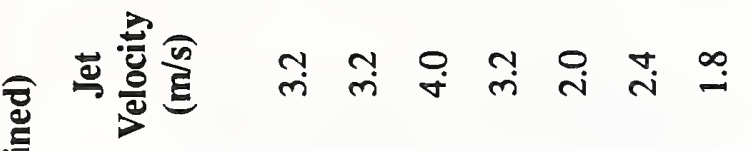

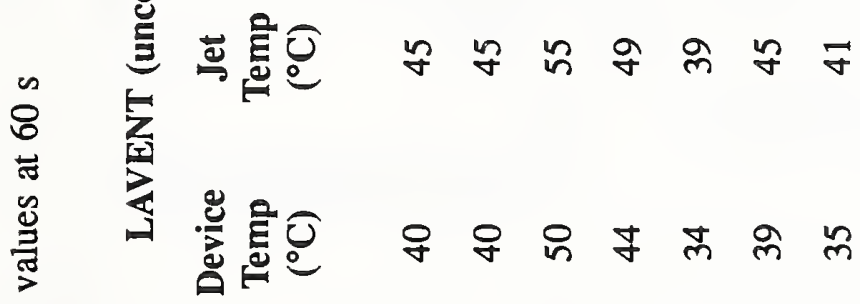

$$
\begin{aligned}
& \text { 罡 }
\end{aligned}
$$

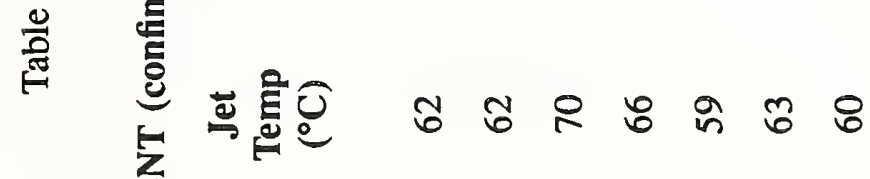

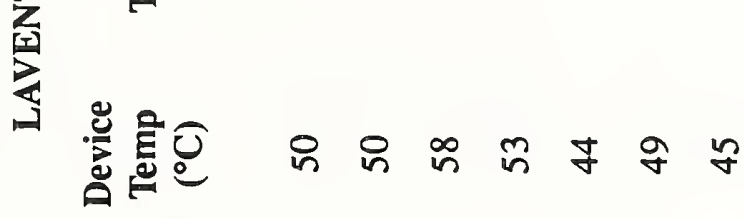

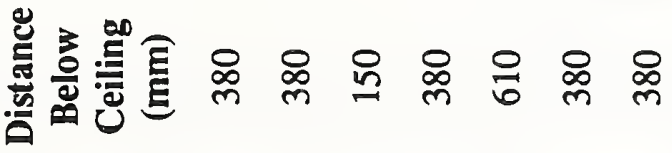

$$
\begin{aligned}
& \text { E } \quad \frac{9}{0} \stackrel{0}{0} \text { กิ }
\end{aligned}
$$

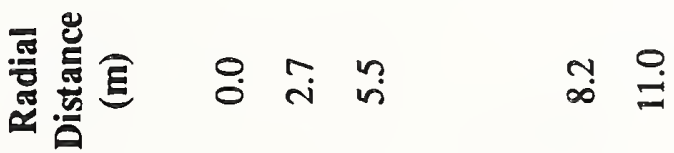




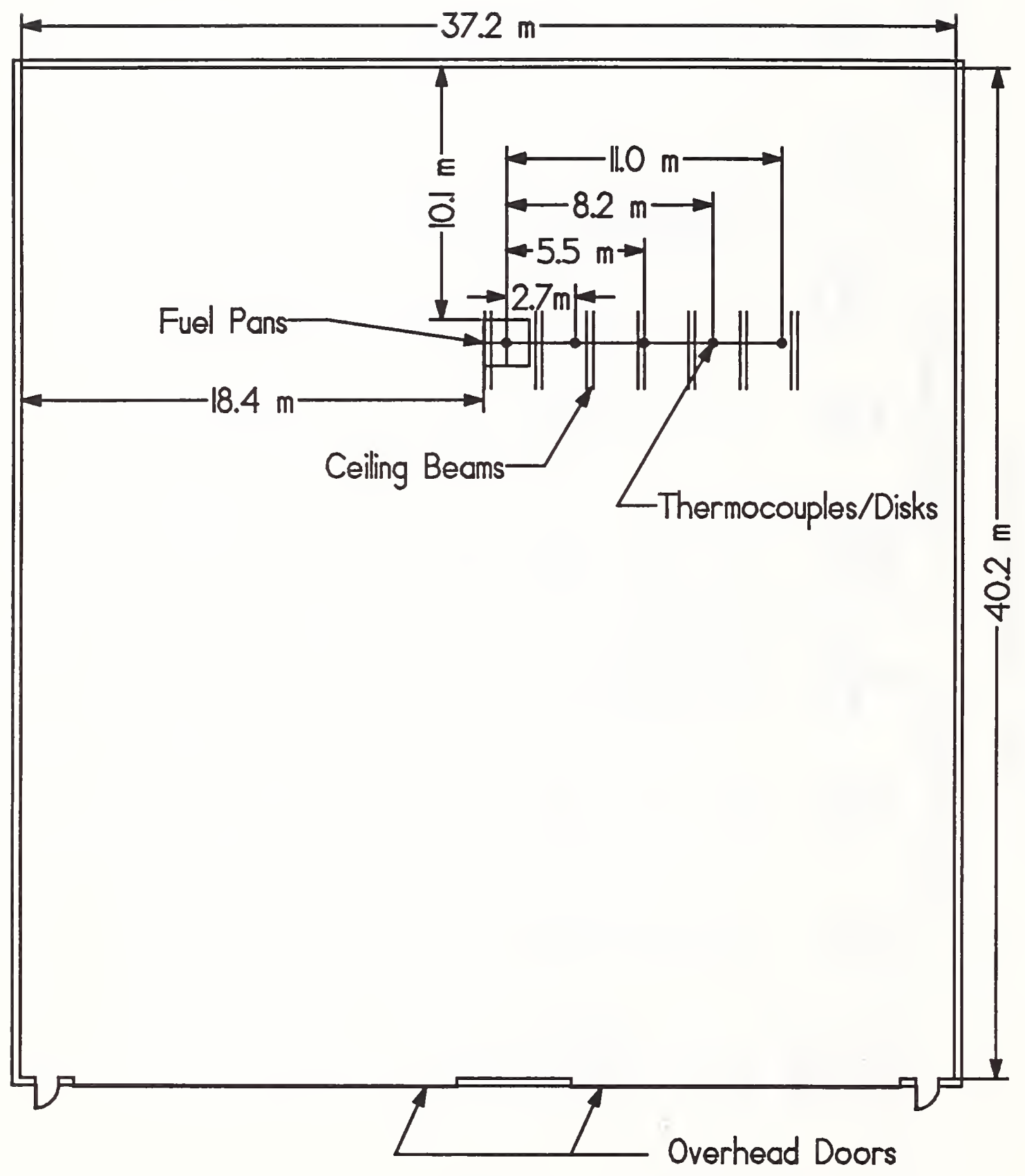

Figure 1. Plan view of main hanger bay 


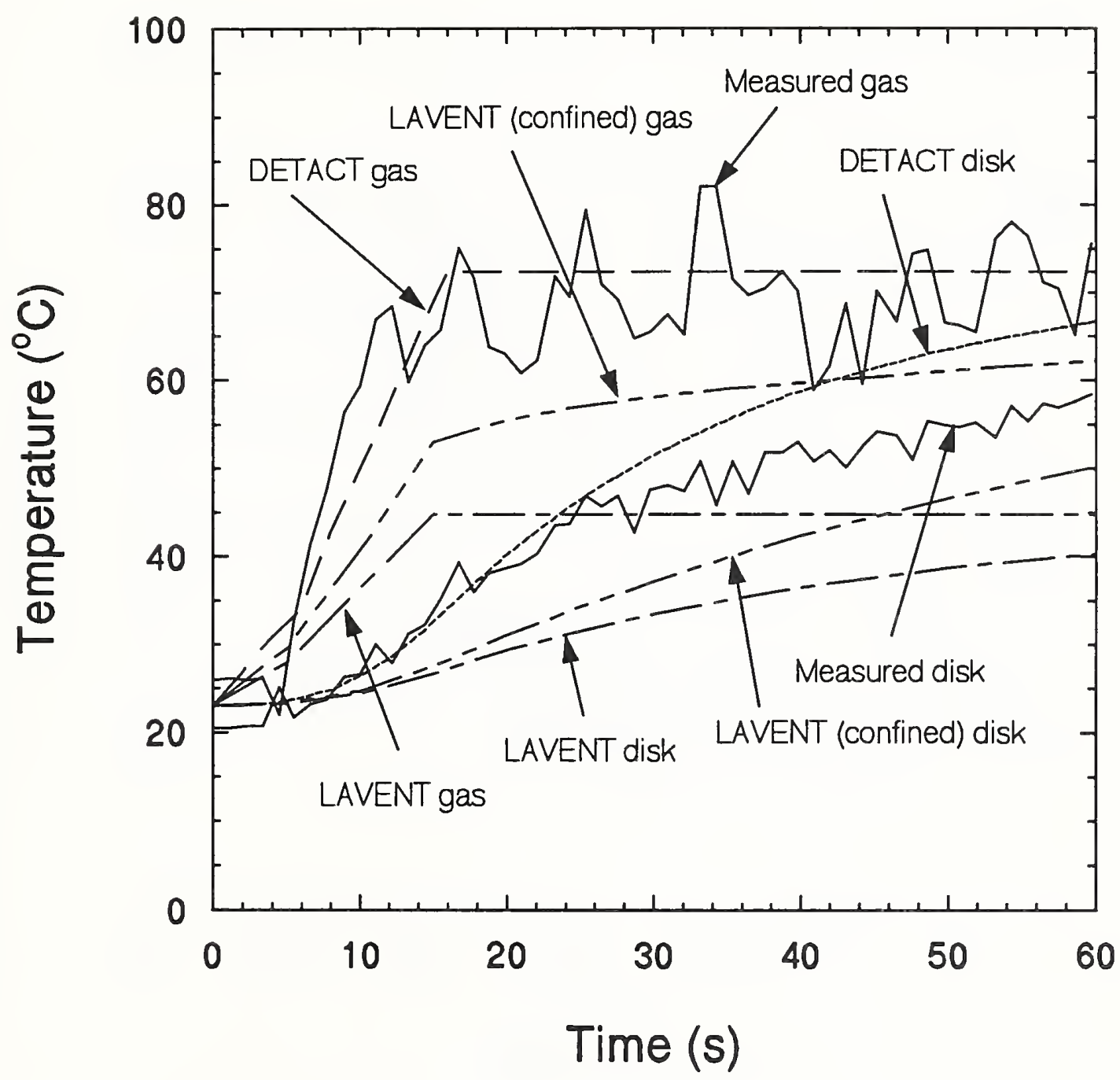

Figure 2. Temperatures at $0 \mathrm{~m}$ radial distance 


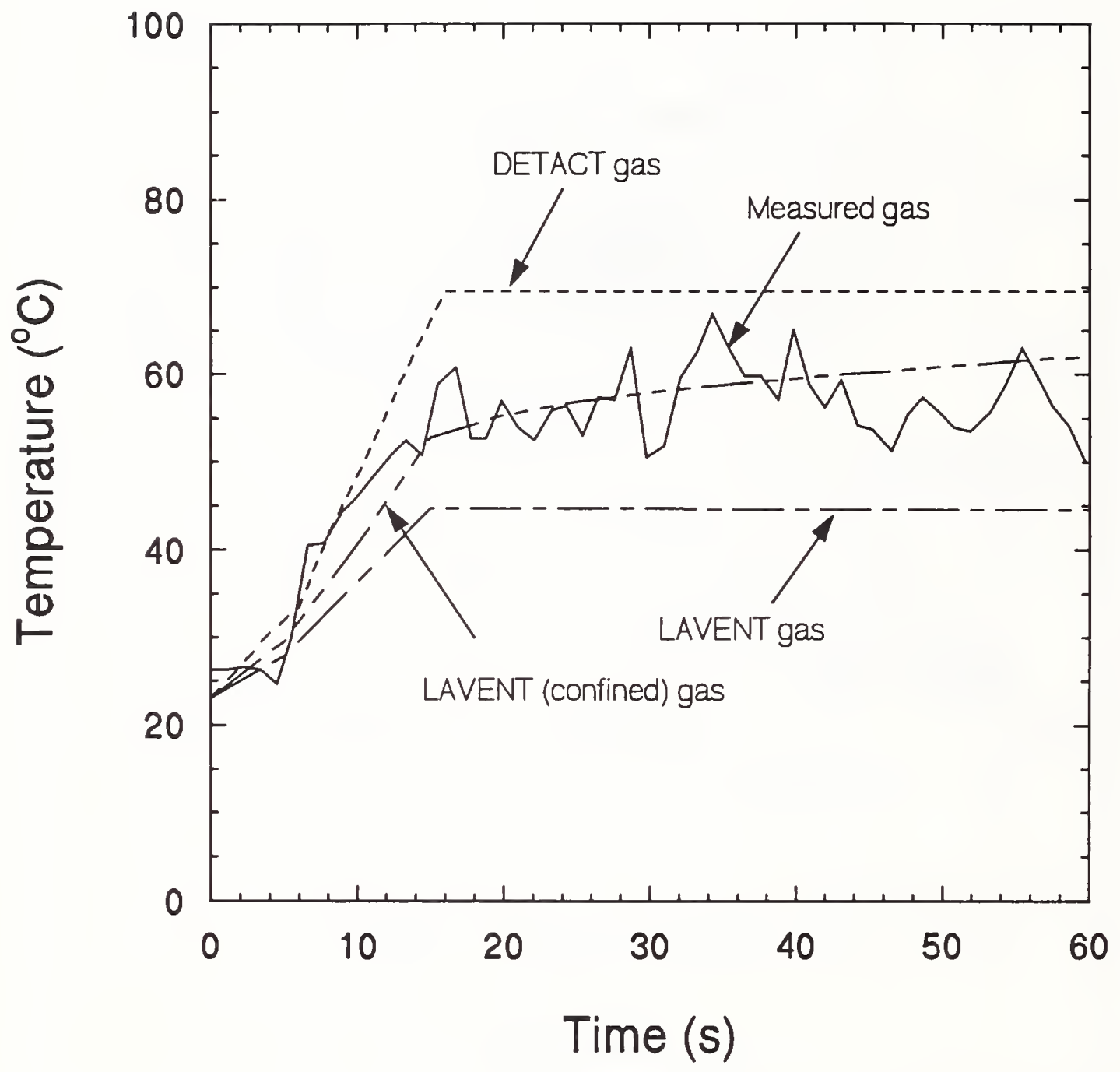

Figure 3. Temperatures at $2.7 \mathrm{~m}$ radial distance 


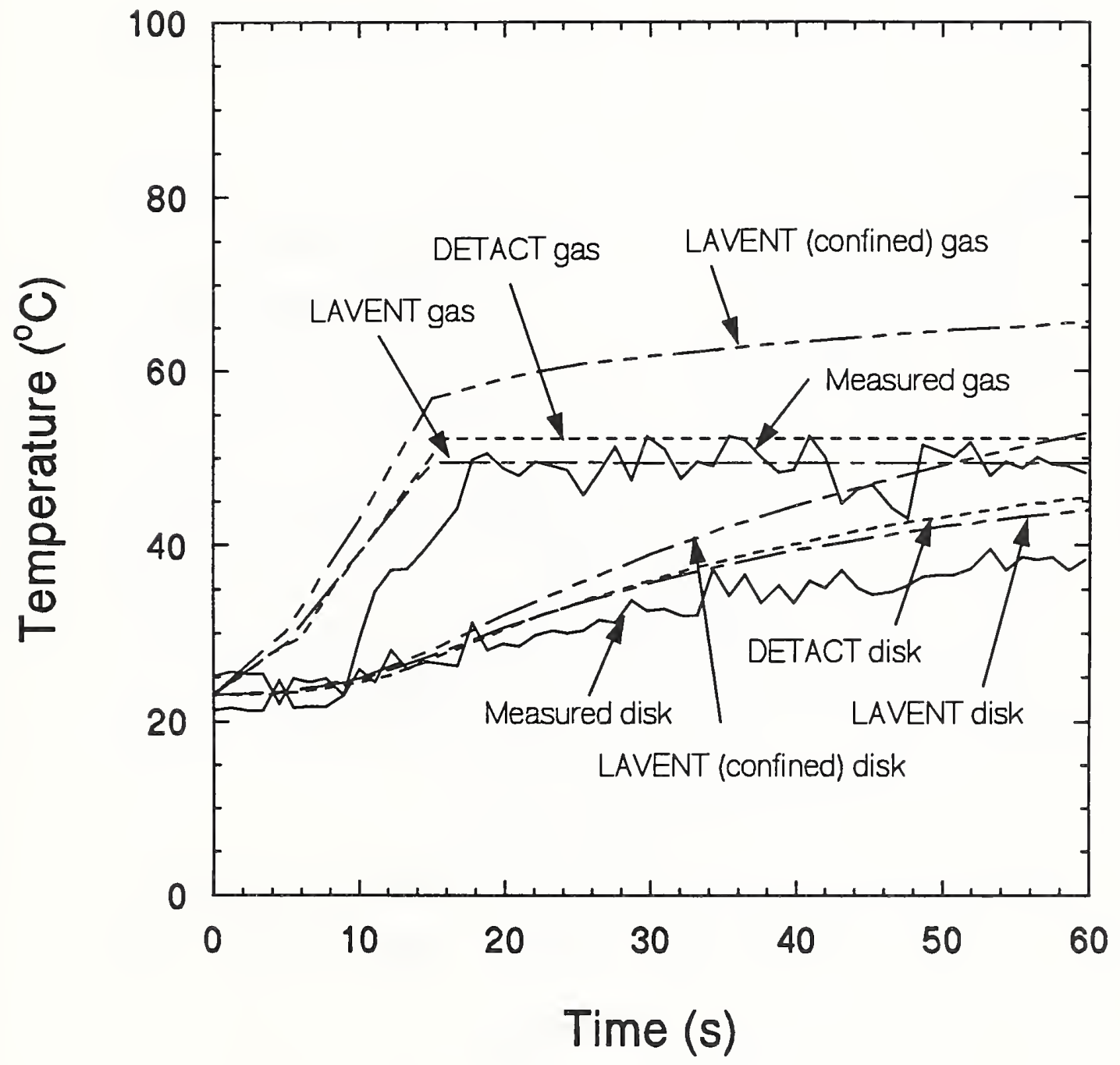

Figure 4. Temperatures at $5.5 \mathrm{~m}$ radial distance 


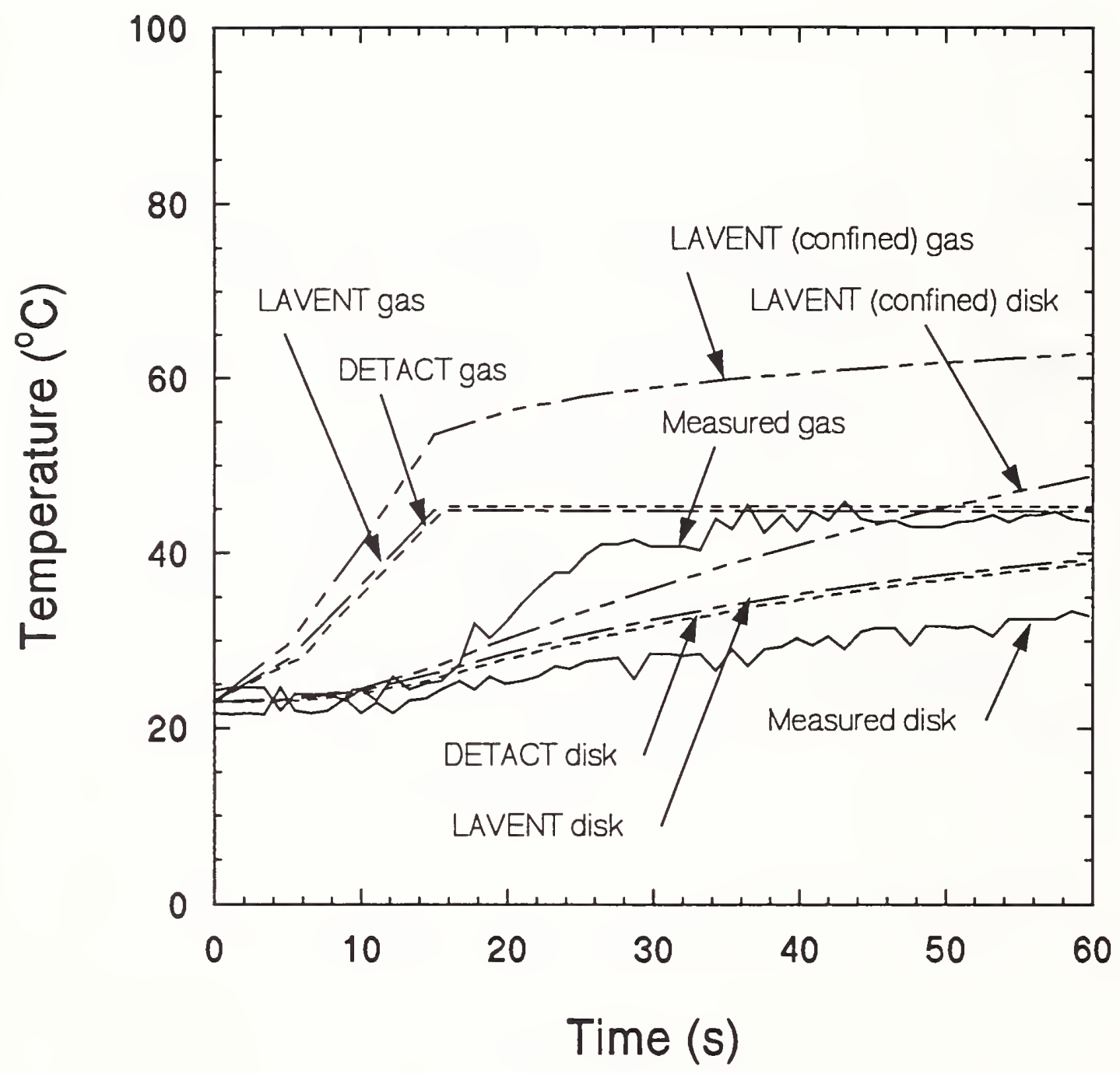

Figure 5. Temperatures at $8.2 \mathrm{~m}$ radial distance 


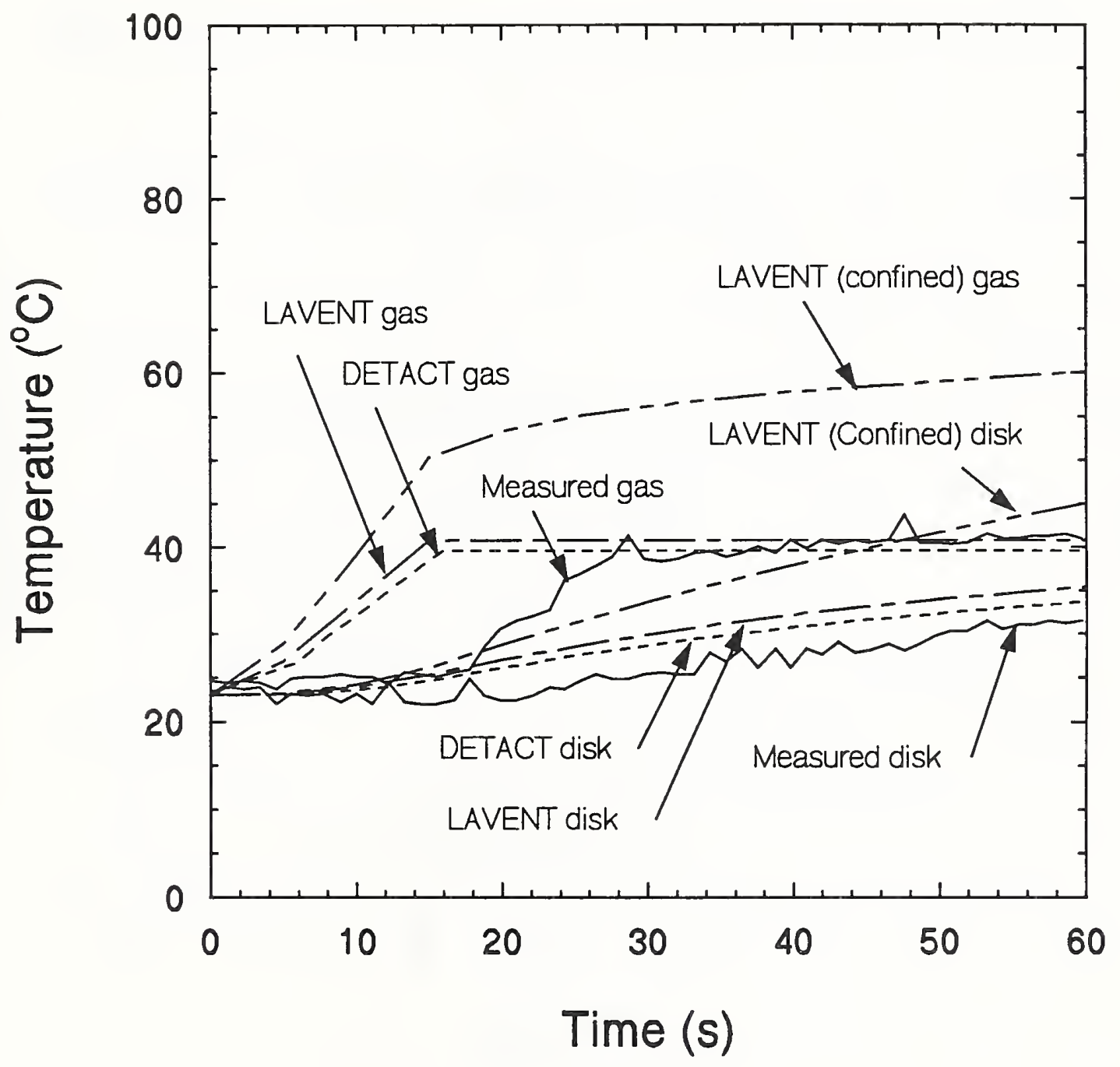

Figure 6. Temperatures at $11.0 \mathrm{~m}$ radial distance 


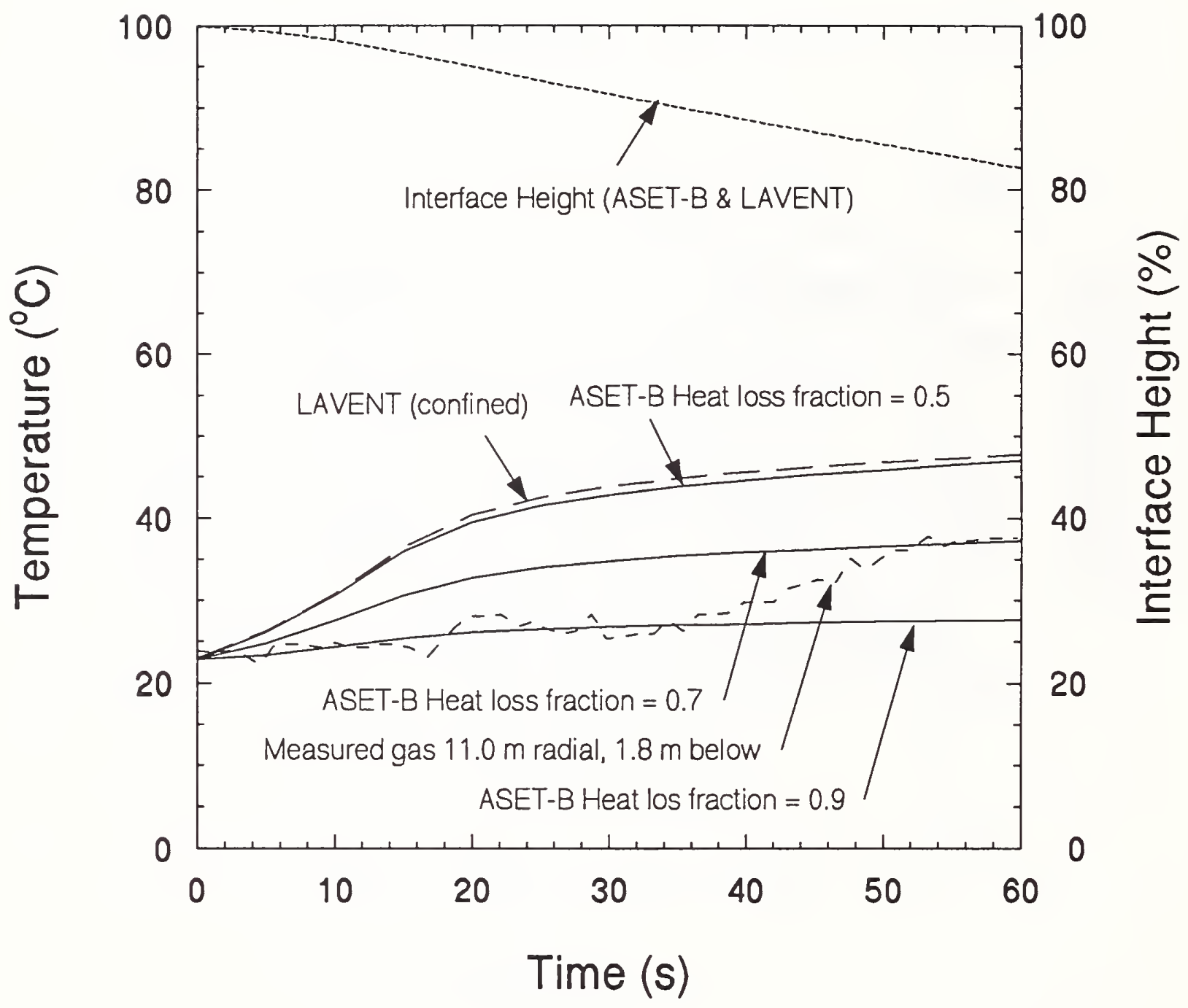

Figure 7. Predicted upper layer temperature 


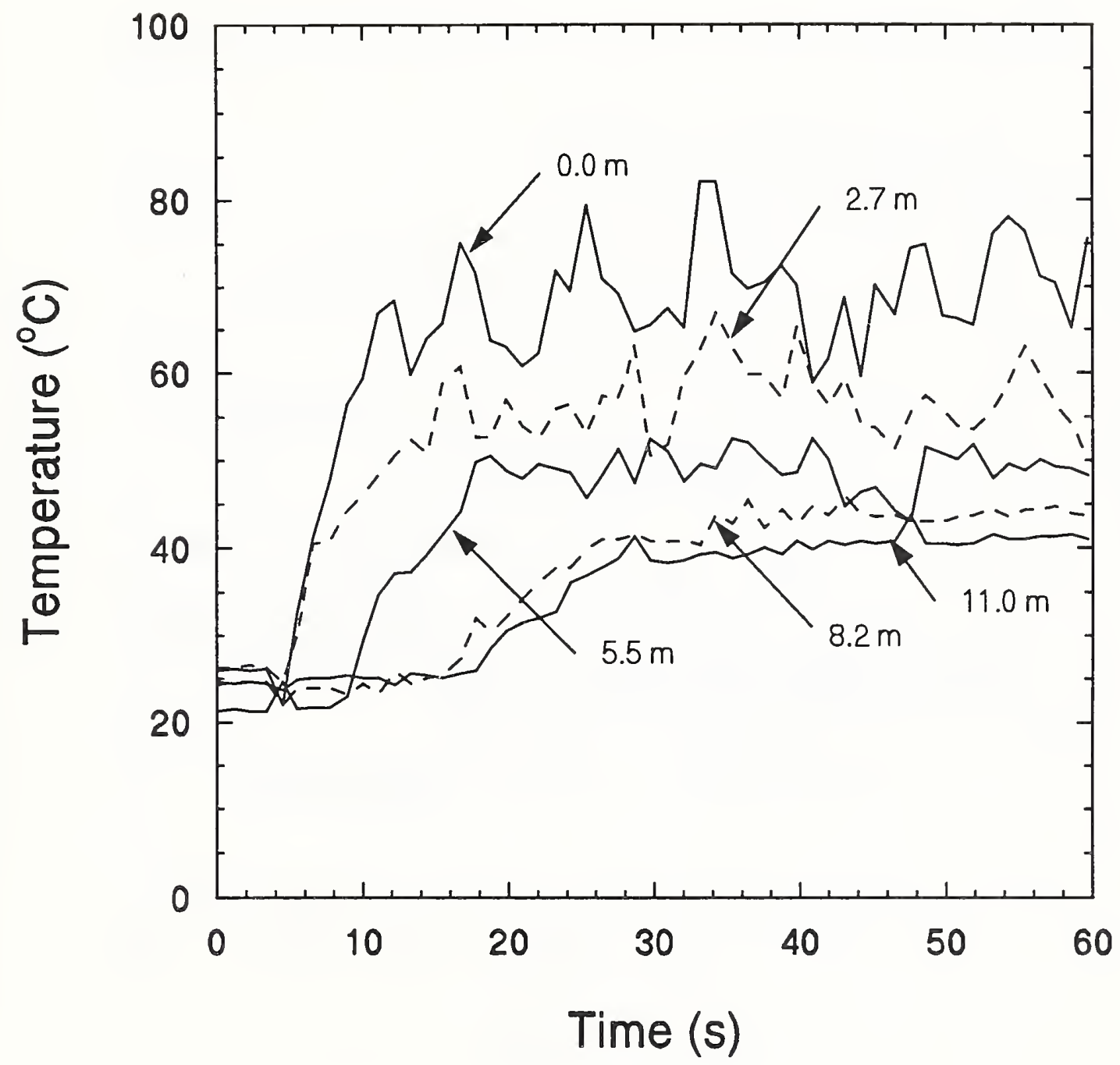

Figure 8. Gas temperatures for all radial distances, $380 \mathrm{~mm}$ below ceiling 


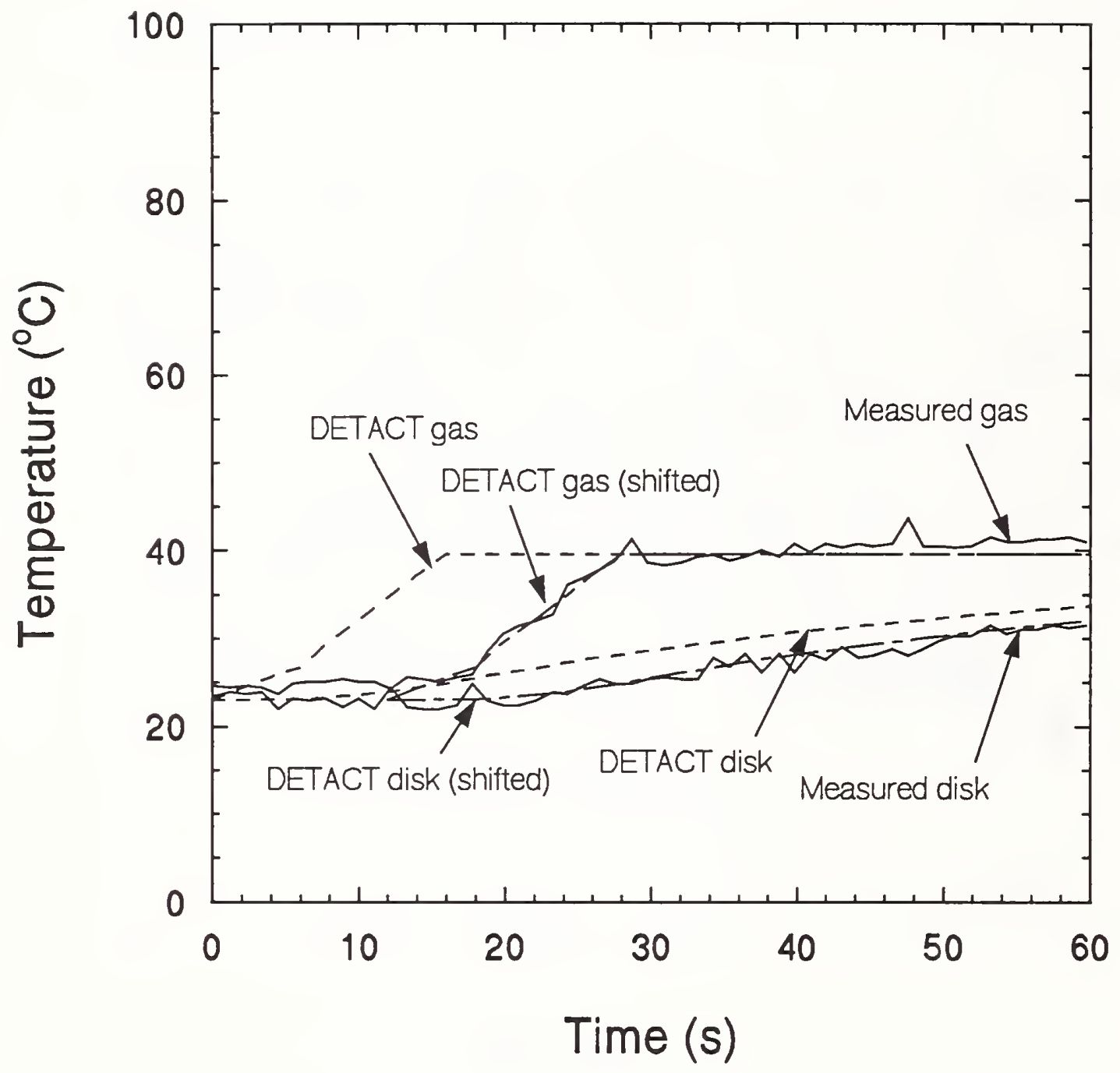

Figure 9. Temperatures at $11.0 \mathrm{~m}$ radial distance with time shift 


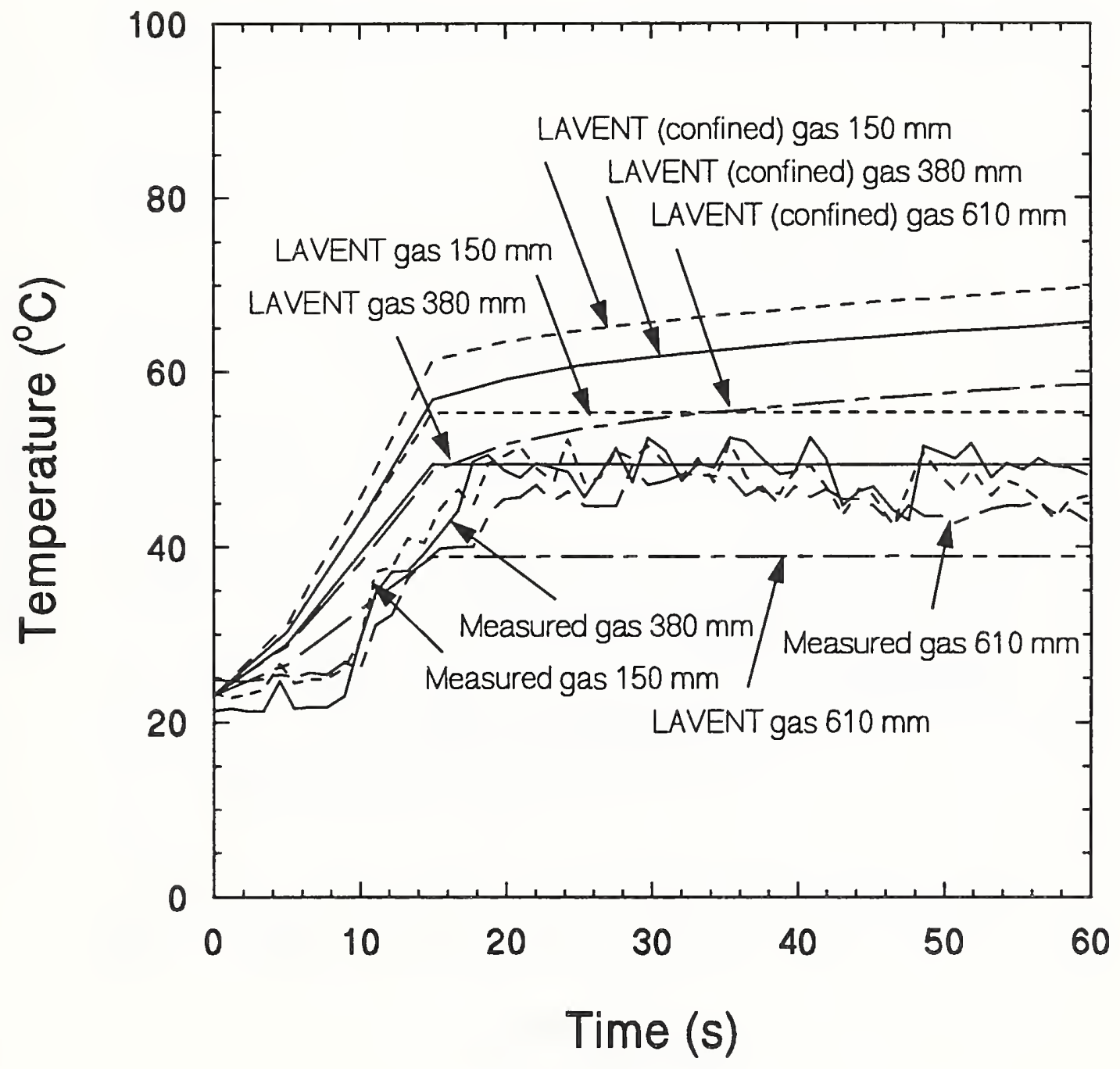

Figure 10. Temperatures at $5.5 \mathrm{~m}$ radial distance at 3 elevations 


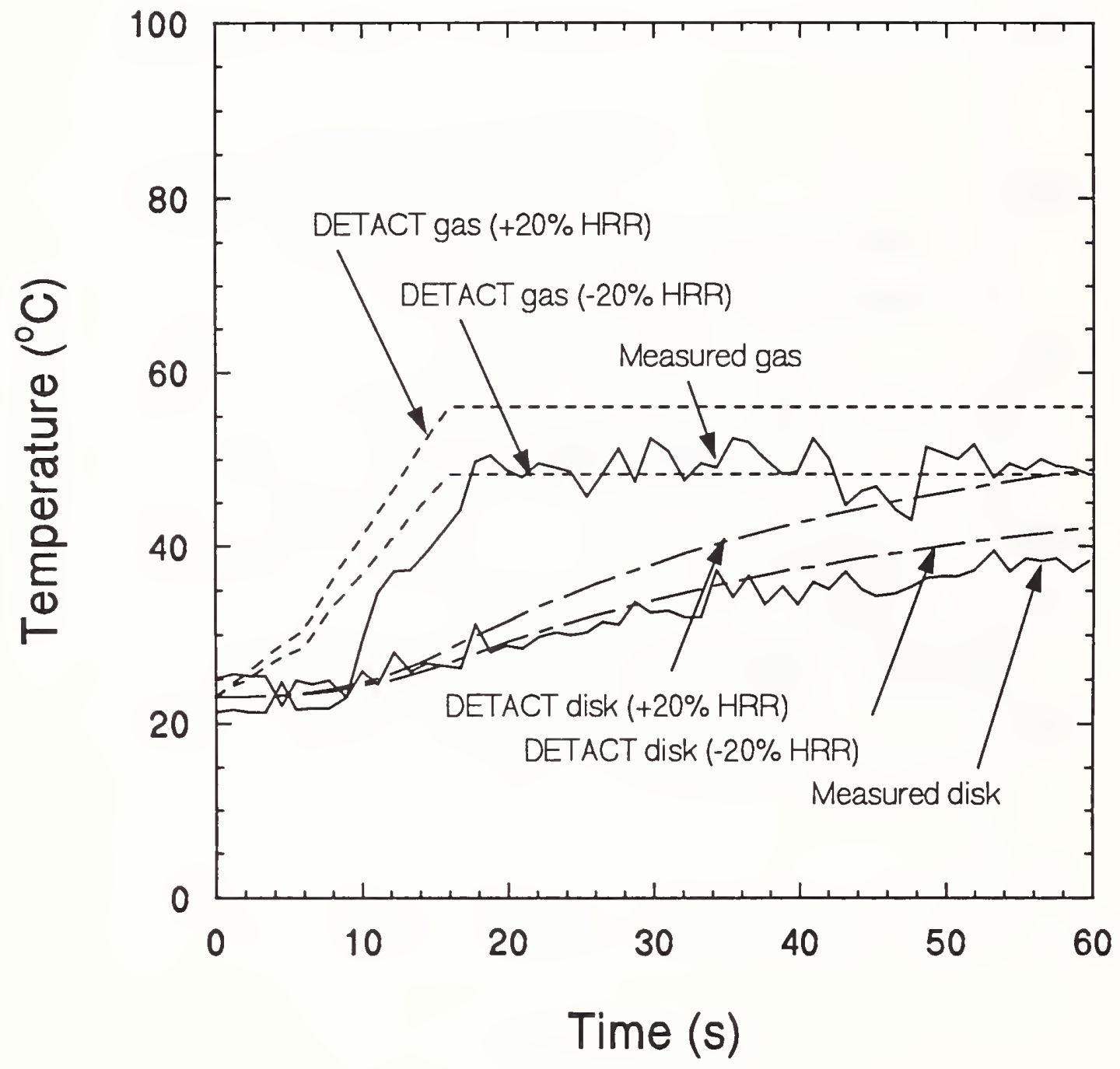

Figure 11. Temperatures at $5.5 \mathrm{~m}$ radial distance with varying heat release rates 


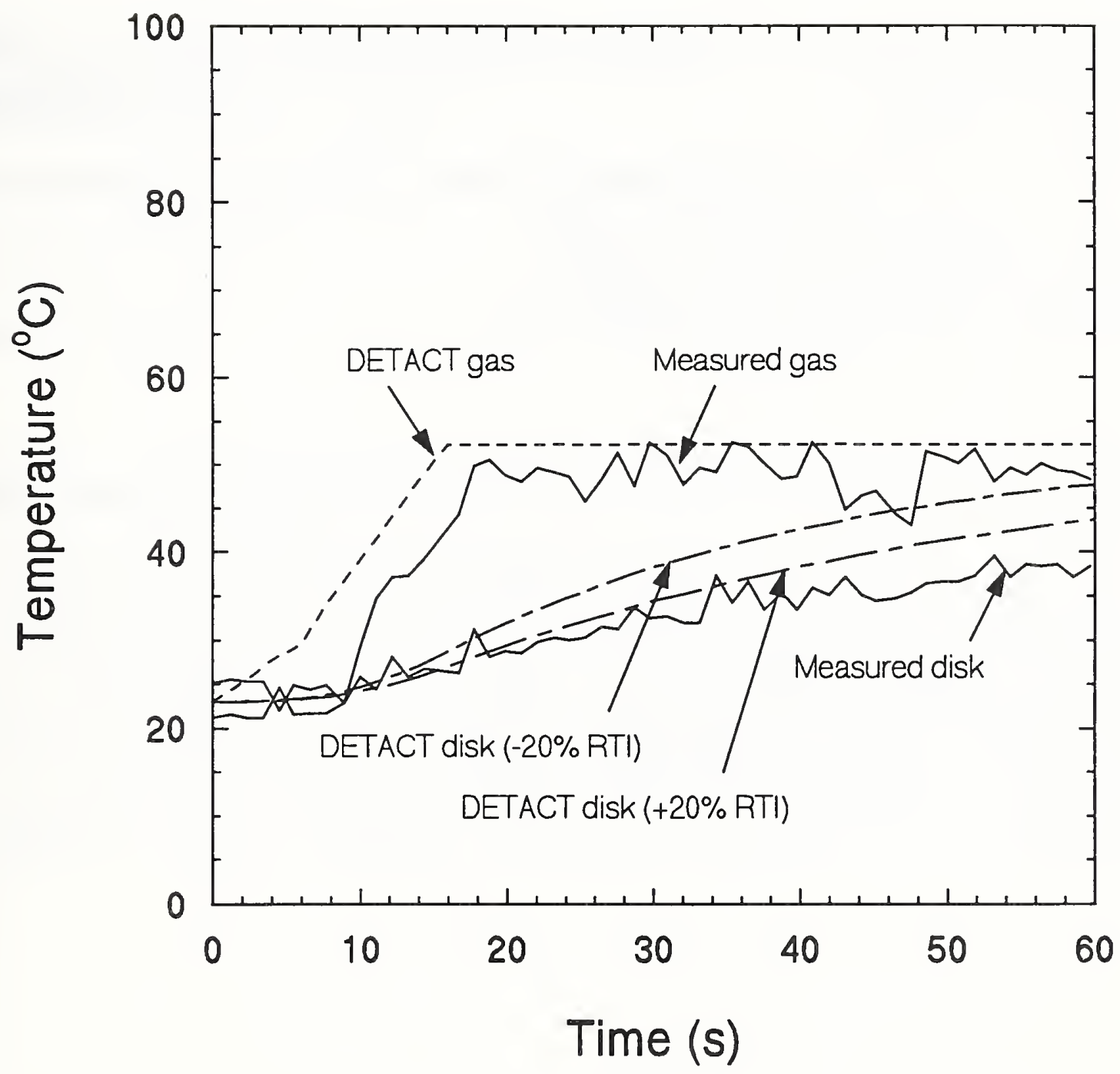

Figure 12. Temperatures at $5.5 \mathrm{~m}$ radial distance with varying RTI 


